\title{
Ketogenesis contributes to intestinal cell differentiation
}

\author{
Qingding Wang ${ }^{1,2}$, Yuning Zhou ${ }^{1}$, Piotr Rychahou ${ }^{1,2}$, Teresa W-M Fan ${ }^{1,3}$, Andrew N Lane ${ }^{1,3}$, Heidi L Weiss ${ }^{1}$ and BMark Evers ${ }^{\star, 1,2}$
}

The intestinal epithelium undergoes a continual process of proliferation, differentiation and apoptosis. Previously, we have shown that the PI3K/Akt/mTOR pathway has a critical role in intestinal homeostasis. However, the downstream targets mediating the effects of mTOR in intestinal cells are not known. Here, we show that the ketone body $\beta$-hydroxybutyrate ( $\beta \mathrm{HB})$, an endogenous inhibitor of histone deacetylases (HDACs) induces intestinal cell differentiation as noted by the increased expression of differentiation markers (Mucin2 (MUC2), lysozyme, IAP, sucrase-isomaltase, KRT20, villin, Caudal-related homeobox transcription factor 2 (CDX2) and p21 ${ }^{\text {Waf1 }}$ ). Conversely, knockdown of the ketogenic mitochondrial enzyme hydroxymethylglutaryl CoA synthase 2 (HMGCS2) attenuated spontaneous differentiation in the human colon cancer cell line Caco-2. Overexpression of HMGCS2, which we found is localized specifically in the more differentiated portions of the intestinal mucosa, increased the expression of CDX2, thus further suggesting the contributory role of HMGCS2 in intestinal differentiation. In addition, mice fed a ketogenic diet demonstrated increased differentiation of intestinal cells as noted by an increase in the enterocyte, goblet and Paneth cell lineages. Moreover, we showed that either knockdown of mTOR or inhibition of mTORC1 with rapamycin increases the expression of HMGCS2 in intestinal cells in vitro and in vivo, suggesting a possible cross-talk between mTOR and HMGCS2/ $\beta$ HB signaling in intestinal cells. In contrast, treatment of intestinal cells with $\beta \mathrm{HB}$ or feeding mice with a ketogenic diet inhibits mTOR signaling in intestinal cells. Together, we provide evidence showing that HMGCS2/ $\beta \mathrm{HB}$ contributes to intestinal cell differentiation. Our results suggest that mTOR acts cooperatively with HMGCS2/ $\beta \mathrm{HB}$ to maintain intestinal homeostasis.

Cell Death and Differentiation (2017) 24, 458-468; doi:10.1038/cdd.2016.142; published online 9 December 2016

The intestinal epithelium undergoes a process of constant and rapid renewal. The intestinal crypts of Lieberkühn, a highly dynamic niche with multipotent stem cells residing in its lower third, generate new cells that eventually differentiate into the four specialized cell types of the small intestine, namely absorptive enterocytes and secretory lineages known as enteroendocrine, goblet and Paneth cells. ${ }^{1,2}$ Differentiated enterocytes, which make up the majority of the cells of the gut mucosa, then undergo a process of apoptosis and are extruded into the lumen. ${ }^{1,3}$ The mechanisms that regulate stem cell maintenance, proliferation, differentiation and apoptosis are precisely orchestrated to ensure proper organ maintenance. ${ }^{3} \mathrm{An}$ imbalance in this highly regimented and orderly process within the intestinal crypts is associated with a number of intestinal pathologies including colorectal cancer, inflammatory bowel disease and necrotizing enterocolitis. ${ }^{4-6}$ To date, the cellular mechanisms regulating intestinal cell differentiation are not entirely known.

Our previous findings identified a central role for PI3K/Akt/ mTOR in intestinal differentiation and proliferation; ${ }^{7-10}$ however, the downstream mediators have not been entirely elucidated. Metabolic changes are now known to have a pivotal role in dictating whether a cell proliferates, differentiates or remains quiescent. ${ }^{11}$ Tissue- and cell-specific metabolic pathways are tightly regulated during development and perform unique functions in specific contexts. ${ }^{11}$ Recent findings have also shown that proliferative cells at the base of the intestinal crypt are characterized by a glycolytic metabolic phenotype, whereas differentiated cells have an oxidative phosphorylation phenotype. ${ }^{12}$

The short chain fatty acid butyrate, a histone deacetylase (HDAC) inhibitor, is known to promote intestinal cell differentiation. ${ }^{13}$ In addition, butyrate has been shown to increase ketone body production through induction of HMGCS2 expression in human intestinal mucosa: ${ }^{14}$ many of the effects of butyrate are likely ketone body dependent. ${ }^{15}$ The synthesis of ketone bodies, such as $\beta$-hydroxybutyrate $(\beta \mathrm{HB})$ and acetoacetate (AcAc), is controlled by the rate-limiting enzyme, mitochondrial 3-hydroxy-3-methylglutaryl-CoA synthase 2 (HMGCS2). ${ }^{16}$ Recently, $\beta \mathrm{HB}$ has also been shown to act as an endogenous inhibitor of HDACs, ${ }^{17}$ which are known to regulate intestinal epithelial differentiation. ${ }^{18}$ Circulating concentrations of $\beta \mathrm{HB}$ can increase to as much as $6-8 \mathrm{mM}$ during prolonged fasting and caloric restriction ${ }^{16,17}$ when the liver switches to fatty acid oxidation, and even to $25 \mathrm{mM}$ in diabetic ketoacidosis. These nutritional states are associated with altered intestinal integrity, ${ }^{19}$ but it is unknown whether ketone bodies have a role in the maintenance of intestinal homeostasis.

Previously, we reported that the TSC2/mTOR signaling pathway has an important role in the maintenance of intestinal homeostasis. In our current study, we found that intestinal cell differentiation is characterized by increased ketogenesis. Moreover, we show that HMGCS2/ $\beta \mathrm{HB}$ has an important role

${ }^{1}$ Markey Cancer Center, University of Kentucky, Lexington, KY, USA; ${ }^{2}$ Department of Surgery, University of Kentucky, Lexington, KY, USA and ${ }^{3}$ Department of Toxicology and Cancer Biology, University of Kentucky, Lexington, KY, USA

${ }^{*}$ Corresponding author: BM Evers, Department of Surgery and Markey Cancer Center, University of Kentucky, 800 Rose Street, CC140, Lexington, KY 40536-0293, USA. Tel: +1 8593236556; Fax: +1 8593232074; E-mail: mark.evers@uky.edu

Received 15.7.16; revised 18.10.16; accepted 04.11.16; Edited by E Gottlieb; published online 09.12.2016 

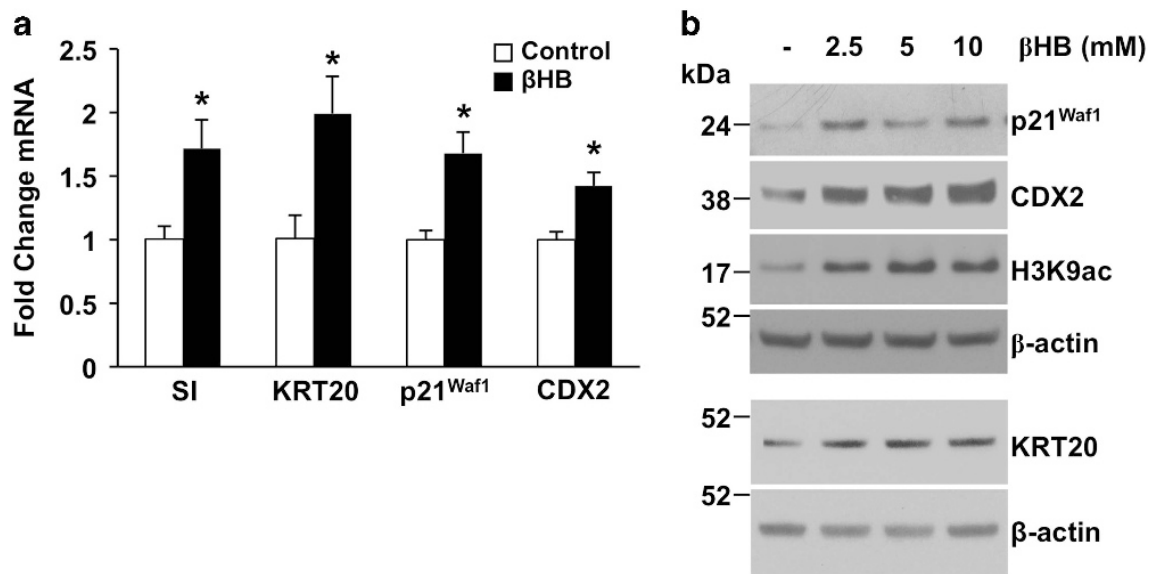

Figure $1 \beta \mathrm{HB}$ increases differentiation in Caco-2 cells. (a) Caco-2 cells were treated with $\beta \mathrm{HB}(10 \mathrm{mM})$ for $48 \mathrm{~h}$. Total RNA was extracted, and SI, KRT20, p21 Waf1 and CDX2 mRNA expression was assessed by real-time RT-PCR. ( $n=3$, data represent mean \pm S.D.; ${ }^{*}<0.01$ versus control). Data are from one of three independent experiments with similar results. (b) Caco-2 cells were treated with $\beta \mathrm{HB}$ at various dosages for $48 \mathrm{~h}$. Cells were lysed and western blot analysis was performed using antibodies against $\mathrm{p} 21^{\text {Waf1 }}$, $\mathrm{CDX} 2, \mathrm{H} 3 \mathrm{~K} 9 \mathrm{ac}, \mathrm{KRT} 20$ and $\beta$-actin. The images are representative of three independent experiments

in the maintenance of intestinal epithelium homeostasis. Thus, aberrant regulation of ketogenesis may result in an imbalance in the proliferation, differentiation and apoptosis patterns within the intestinal crypts, which is associated with a number of intestinal pathologies.

\section{Results}

Intestinal cell differentiation is characterized by increased ketogenesis. To determine whether proliferating and differentiated cells demonstrate distinct metabolic patterns, we used ${ }^{13} \mathrm{C}$-glucose and ${ }^{13} \mathrm{C}$-glutamine stable isotope resolved metabolomics (SIRMs) to map metabolic changes in cultured Caco-2 cells as they undergo differentiation. ${ }^{20}$ Differentiation of Caco-2 cells elicited pronounced changes in central metabolism involving both glucose and glutamine utilization (Supplementary Figure 1). Analysis of the media showed that, upon differentiation, there was a marked decrease in glucose consumption and lactic fermentation. In addition, we observed a decrease in consumption of amino acids, particularly glutamine and valine. This is consistent with an overall decrease in metabolic activity as a consequence of differentiation.

Analysis of the intracellular metabolites showed that the decreased steady-state levels of intracellular metabolites, such as citrate and malate, were noted with differentiation (Supplementary Figure 1). Interestingly, increased amounts of total and of ${ }^{13} \mathrm{C}$-enriched $\beta \mathrm{HB}$ were noted in the differentiated cells grown in the presence of $\left[\mathrm{U}-{ }^{13} \mathrm{C}\right]$-glucose. We observed an increase of both $\mathrm{m} 2$ and $\mathrm{m} 4 \beta \mathrm{HB}$ (Supplementary Figure 1, insert) consistent with condensation of ${ }^{13} \mathrm{C}$-enriched acetyl $\mathrm{CoA}(\mathrm{AcCoA})$ with either unlabeled $\mathrm{AcCoA}$ or glucose-derived ${ }^{13} \mathrm{C}$-enriched $\mathrm{AcCoA}$. Furthermore, $\beta \mathrm{HB}$ was not present in significant amounts in the media, suggesting that it is not exported out of the cell, nor was there obvious cell death. These novel findings demonstrate that glucose-derived carbon has entered the pathway acetyl $\mathrm{CoA} \rightarrow \mathrm{AcAc} \rightarrow \beta \mathrm{HB}$ in the differentiated cells and an enhanced ketogenesis occurs with intestinal cell differentiation. In contrast, there was insignificant incorporation of glutamine-derived ${ }^{13} \mathrm{C}$ into $\beta \mathrm{HB}$ (data not shown).

$\boldsymbol{\beta} \mathrm{HB}$ induces enterocyte differentiation in Caco- 2 cells. Caco-2 cells can differentiate into an enterocyte-like phenotype, either with treatment by HDAC inhibitors or spontaneously with overconfluence, characterized by a polarized monolayer and the expression of cytokeratin 20 (KRT20) and the brush-border enzymes such as sucrase-isomaltase (SI). ${ }^{21,22}$

To determine whether $\beta \mathrm{HB}$ has a role in human intestinal cell differentiation, Caco- 2 cells were treated with $\beta \mathrm{HB}$ for $48 \mathrm{~h}$ and the mRNA levels of the enterocyte markers SI and KRT20 were determined. As shown in Figure 1a, treatment of Caco-2 cells with $\beta \mathrm{HB}$-induced SI and KRT20 mRNA expression, suggesting that $\beta \mathrm{HB}$ increases enterocyte differentiation. p21 Waf1 inhibits intestinal cell growth and induces differentiation; ${ }^{23}$ Caudal-related homeobox transcription factor 2 (CDX2) is an intestine-specific transcription factor regulating homeostasis of the continuously renewing intestinal epithelium. ${ }^{24}$ We found that treatment with $\beta \mathrm{HB}$ also increased $\mathrm{p} 21^{\text {Waf1 }}$ and CDX2 mRNA (Figure 1a) and protein expression (Figure 1b). Furthermore, HDAC inhibition by $\beta \mathrm{HB}$ was shown by the increased acetylation of histone $\mathrm{H} 3$ lysine 9 (H3K9ac) (Figure 1b). Consistent with the increased mRNA expression, treatment with $\beta \mathrm{HB}$ increased KRT20 protein expression in Caco- 2 cells (Figure $1 b$ ). These results indicate that $\beta \mathrm{HB}$, which is increased with intestinal cell differentiation, acts as an endogenous inhibitor of HDACs inducing intestinal cell differentiation.

Knockdown of the ketone biosynthetic enzyme HMGCS2 inhibits enterocyte differentiation in Caco-2 cells. We have shown that treatment with $\beta \mathrm{HB}$ induces enterocytic differentiation in Caco- 2 cells and that synthesis of $\beta \mathrm{HB}$ is increased in differentiated Caco- 2 cells. $\beta \mathrm{HB}$ synthesis is dependent on the activity of mitochondrial HMGCS2. ${ }^{25}$ To 

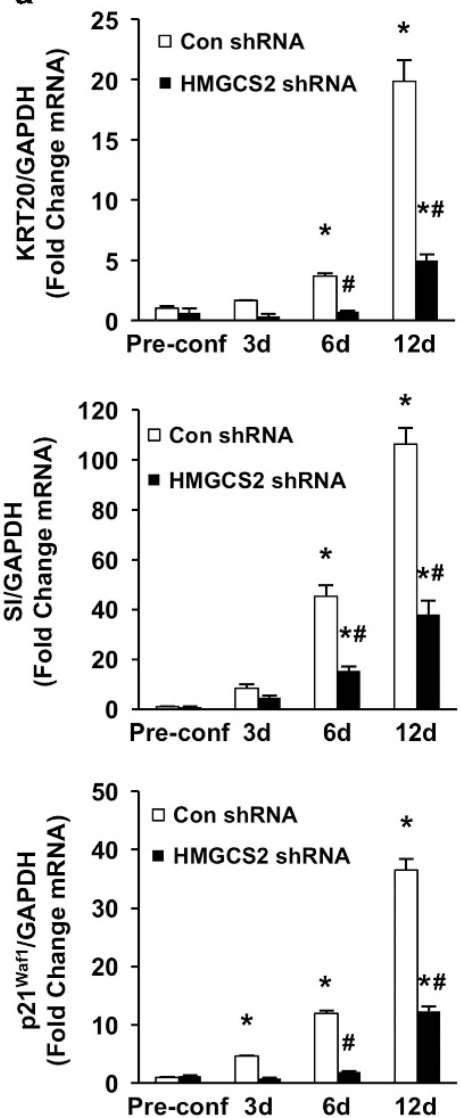

b

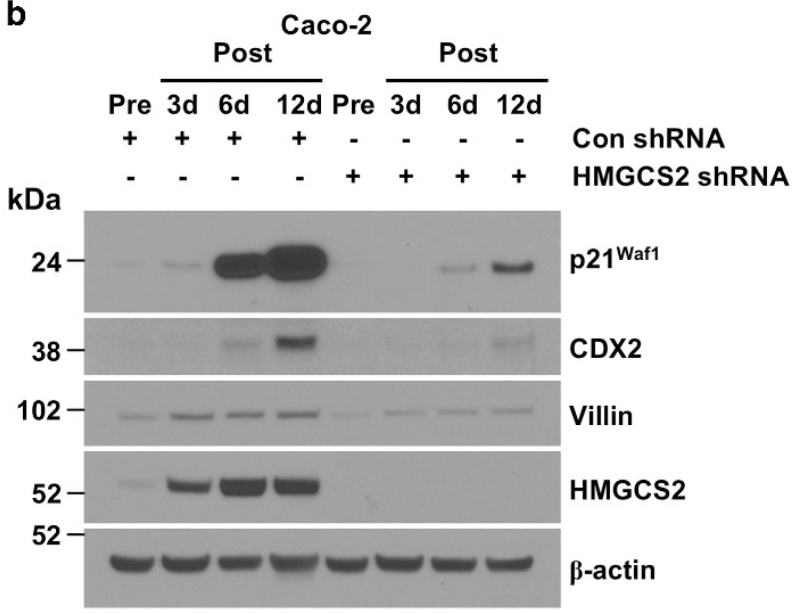

Figure 2 Knockdown of HMGCS2 attenuates spontaneous differentiation of Caco-2 cells. Caco-2 cells, stably transfected with control or HMGCS2 shRNA, were incubated 3 , 6 and 12 days after confluency to differentiation. (a) Total RNA was extracted, and SI, KRT20 and p21 War1 mRNA expression was assessed by real-time RT-PCR. ( $n=3$, data represent mean \pm S.D.; ${ }^{*} P<0.01$ versus pre-confluent; ${ }^{\#} P<0.01$ versus control shRNA). Data are from one of three independent experiments with similar results. (b) Cells were lysed and western blot analysis was performed using antibodies against $\mathrm{p} 21^{\text {Waf1 }}, \mathrm{CDX} 2$, villin, HMGCS2 and $\beta$-actin. The images are representative of three independent experiments

determine the role of HMGCS2 in intestinal cell differentiation, we transfected pre-confluent Caco-2 cells with shRNA directed against HMGCS2 mRNA to determine whether loss of HMGCS2 can attenuate the differentiated phenotype associated with post-confluence. Caco-2 cell lines with stable HMGCS2 knockdown were cultured and harvested at different time points: pre-confluent (pre) or 3, 6 and 12 days post-confluent. As shown in Figure 2, spontaneous Caco-2 differentiation was shown by the increased mRNA expression of SI, KRT20 and p2 $1^{\text {Waf1 }}$ as determined by real-time RTPCR (Figure 2a), and increased protein expression of p21 Waf1 CDX2 and villin as determined by western blotting (Figure 2b); these increases were significantly attenuated by knockdown of HMGCS2, suggesting that HMGCS2 is required for Caco-2 spontaneous differentiation. In agreement with the increase of $\beta \mathrm{HB}$, expression of HMGCS2 protein is markedly increased with spontaneous Caco-2 cell differentiation (Figure 2b).

HMGCS2/ $\beta$ HB contributes to the induction of goblet and Paneth cell marker expression. Treatment with butyrate, an HDAC inhibitor, induces differentiation as noted by the increased expression of intestinal alkaline phosphatase (IAP), an enterocyte differentiation marker, and Mucin2 (MUC2), a goblet cell differentiation marker in LS174T cells. ${ }^{26,27}$ We have shown that $\beta \mathrm{HB}$ inhibits HDAC in Caco2 cells. To determine whether $\beta \mathrm{HB}$ also increases goblet cell differentiation, we treated LS174T cells with $\beta \mathrm{HB}$. As shown in Figure 3, treatment of LS174T with $10 \mathrm{mM} \beta \mathrm{HB}$ increased not only the expression of KRT20 and IAP but also increased the expression of MUC2 and p21 Waf1 and CDX2 (Figures 3a and $b$ ). The inhibition of HDAC by $\beta$ HB was demonstrated by increased expression of $\mathrm{H} 3 \mathrm{~K} 9 \mathrm{ac}$ (Figure $3 \mathrm{~b}$ ).

To determine whether $\beta \mathrm{HB}$ also contributes to Paneth cell differentiation, we next treated HT29 cells with $\beta$ HB. HT29 cells produce IAP, and treatment with butyrate increases expression of IAP in HT29 cells. ${ }^{21}$ In addition, HT29 cells produce MUC2 ${ }^{9}$ and lysozyme (LYZ) (a differentiation marker of Paneth cells). ${ }^{28}$ Treatment of HT29 cells with $\beta \mathrm{HB}$ increased the mRNA (Figure 4a) and/or protein levels (Figure 4b) of IAP, MUC2, LYZ and p21 Waf1 and CDX2 and protein levels of $\mathrm{H} 3 \mathrm{~K} 9 \mathrm{ac}$. Taken together, these novel results suggest that $\beta \mathrm{HB}$ is an endogenous inhibitor of HDACs and an inducer of intestinal cell differentiation. 

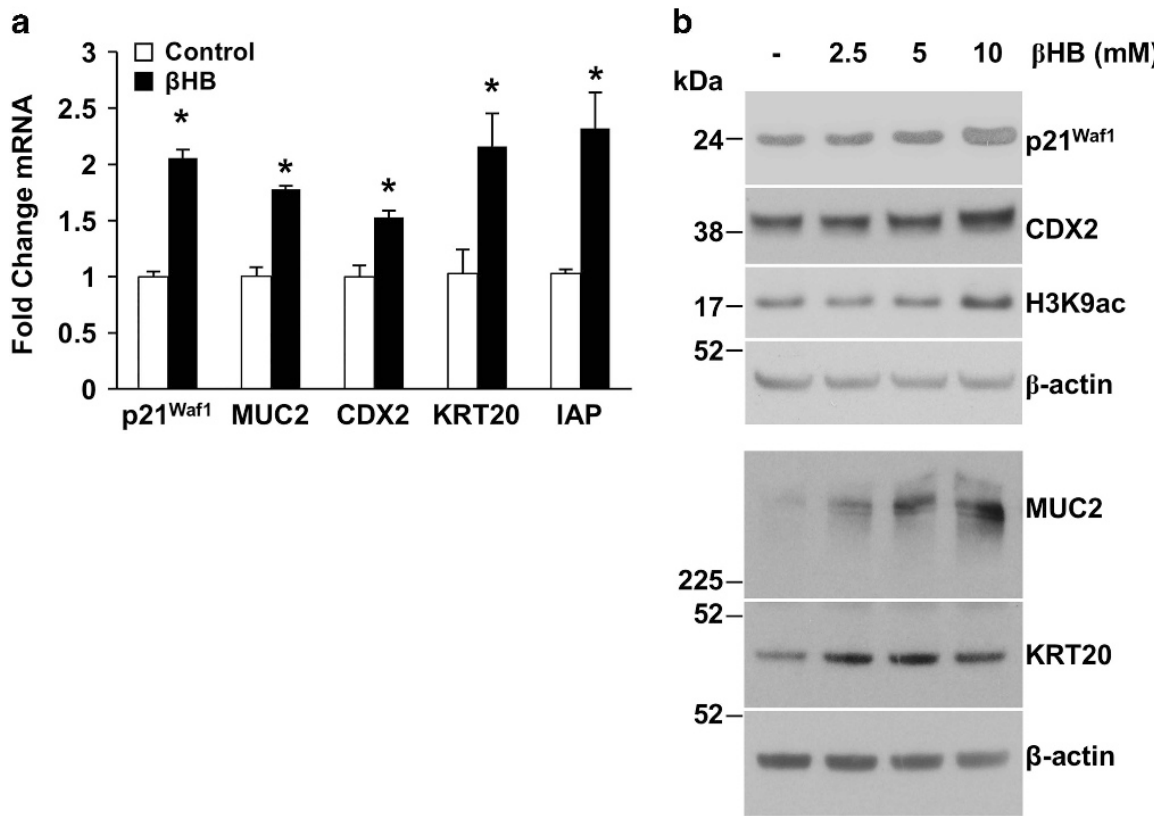

Figure $3 \beta \mathrm{HB}$ increases the expression of enterocyte and goblet cell markers in LS174T cells. LS174T cells were treated with $\beta$ HB (10 mM) for $48 \mathrm{~h}$. Total RNA was extracted, and IAP (enterocyte marker) and KRT20 (enterocyte marker), MUC2 (goblet cell marker), p21 Waf1 and CDX2 mRNA expression was assessed by real-time RT-PCR. $\left(n=3\right.$, data represent mean \pm S.D.; ${ }^{*} P<0.01$ versus control). Data are from one of three independent experiments with similar results. (b) LS174T cells were treated with $\beta$ HB at various dosages for $48 \mathrm{~h}$. Cells were lysed and western blot analysis was performed using antibodies against p21 ${ }^{\text {waf1 }}$, CDX2, H3K9ac, MUC2, KRT20 and $\beta$-actin. The images are representative of three independent experiments
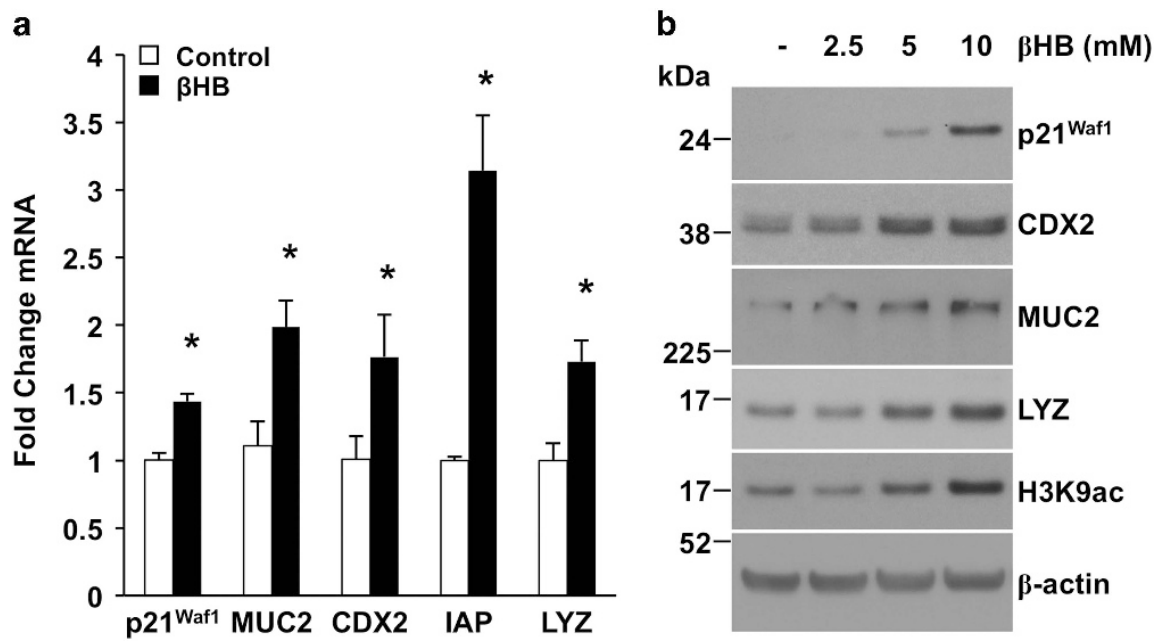

Figure $4 \beta \mathrm{HB}$ induces the expression of enterocyte, goblet and Paneth cell markers in HT29 cells. HT29 cells were treated with $\beta \mathrm{HB}$ (10 mM) for $48 \mathrm{~h}$. Total RNA was extracted, and MUC2 (goblet cell marker), IAP (enterocyte marker), LYZ (Paneth cell marker), p21 ${ }^{\text {Waf1 }}$ and CDX2 mRNA expression was assessed by real-time RT-PCR. ( $n=3$, data represent mean + S.D.: ${ }^{*} P<0.01$ versus control). Data are from one of at least three independent experiments with similar results. (b) HT29 cells were treated with $\beta$ HB at various dosages for $48 \mathrm{~h}$. Cells were lysed and western blot analysis was performed using antibodies against p21 ${ }^{\text {Waf1 }}, \mathrm{CDX} 2, \mathrm{MUC2}$, LYZ, H3K9ac and $\beta$-actin. The images are representative of three independent experiments

To test the effect of $\beta \mathrm{HB}$ on cell proliferation and apoptosis along with the increased differentiation, LS174T and HT29 cells were treated with $\beta \mathrm{HB}$ and cell numbers were counted. $\beta \mathrm{HB}$ treatment inhibited HT29 and LS174T cell proliferation (Supplementary Figures 2A and B). There was no apparent increase in apoptosis (as determined by caspase-3 cleavage and DNA fragmentation) after treatment with $\beta \mathrm{HB}$ at same dosages for $48 \mathrm{~h}$ (data not shown).

To delineate the role of HMGCS2 in the regulation of intestinal cell differentiation more precisely, we overexpressed HMGCS2 in Caco-2 and LS174T cells. Overexpression of HMGCS2 increased expression of p21 Waf1, CDX2 and 

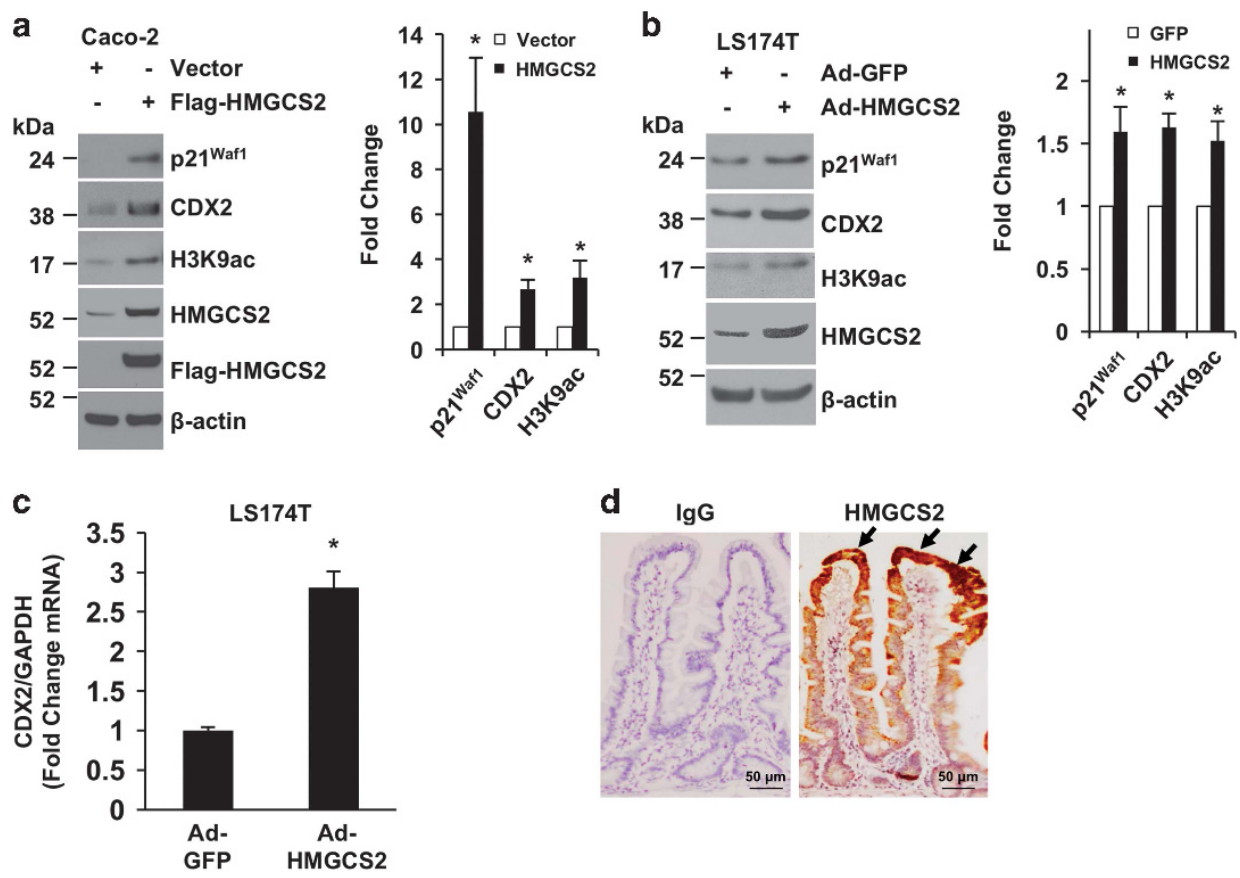

Figure 5 HMGCS2 contributes to intestinal differentiation. (a) Caco-2 cells were transfected with empty vector (control) or transfected with Flag-HMGCS2 constructs. After $48 \mathrm{~h}$, cells were lysed and extracted for protein. p21 ${ }^{\text {Waf1 }}$, CDX2, H3K9ac, HMGCS2, Flag-tagged HMGCS2 and $\beta$-actin were determined by western blotting. The images are representative of three independent experiments. p21 ${ }^{\text {Waf1 }}, \mathrm{CDX} 2$ and $\mathrm{H} 3 \mathrm{~K} 9 \mathrm{ac}$ signals from three separate experiments were quantitated densitometrically and expressed as fold change with respect to $\beta$-actin. ( $n=3$, data represent mean \pm S.D.; ${ }^{*} P<0.01$ versus control vector). (b and $\left.\mathbf{c}\right)$ LS174T cells were infected with a recombinant adenovirus encoding the human HMGCS2 or vector control encoding GFP. After $48 \mathrm{~h}$, cells were lysed and extracted for RNA and protein. (b) p21 War1, CDX2, H3K9ac, HMGCS2 and $\beta$-actin were determined by western blotting. The images are representative of three independent experiments. p21 ${ }^{\text {Waf1 }}, \mathrm{CDX} 2$ and $\mathrm{H} 3 \mathrm{~K} 9 \mathrm{ac}$ signals from three separate experiments were quantitated densitometrically and expressed as fold change with respect to $\beta$-actin. ( $n=3$, data represent mean \pm S.D.; ${ }^{*} P<0.01$ versus GFP control). (c) CDX2 mRNA expression was assessed by real-time RT-PCR. ( $n=3$, data represent mean \pm S.D.; * $P<0.01$ versus GFP control). Data are from one of three independent experiments with similar results. Overexpression of HMGCS2 inhibits HDAC and increases p21 Waf1 and CDX2 expression in Caco-2 and LS174T cells. (d) Immunohistochemical analysis of HMGCS2 protein expression in normal human small intestine. Human normal small intestine sections were fixed and stained with primary anti-human HMGCS2 antibody. HMGCS2 is specifically expressed in the more differentiated region (i.e., villus; arrows). Scale bars $=50 \mu \mathrm{m}$. The images are representative of five cases

H3K9ac in Caco-2 (Figure 5a) and LS174T cells (Figures 5b and $\mathrm{c}$ ). These results further indicate that, similar to our findings by treatment of intestinal cells with $\beta \mathrm{HB}$, HMGCS2 contributes to the differentiation process.

Finally, to correlate the expression pattern of HMGCS2 protein in the human intestine, sections of adjacent normal human small bowel were obtained from five adult patients following intestinal resection for GI pathology (Supplementary Table 1). Intense staining for HMGCS2 was localized to the most differentiated region of the intestine (i.e., villus), which correlates with our in vitro results by linking increased HMGCS2 expression with the most highly differentiated region of the intestinal mucosa (Figure $5 \mathrm{~d}$ ).

Feeding a ketogenic diet to mice enhances intestinal differentiation. We next determined whether the increased ketogenesis enhances the differentiation in the epithelium of mouse intestine. Mice fed with ketogenic diets demonstrate elevated HMGCS2/ $\beta \mathrm{HB}$ levels in tissues including the intestine. ${ }^{29,30}$ 1,3-Butanediol, a ketone body precursor, is metabolized by alcohol dehydrogenase and aldehyde dehydrogenases to $\beta \mathrm{HB} .{ }^{31}$ We fed mice with a ketogenic diet (normal chow diet mixed with 1,3-butanediol ketone diesters $)^{30}$ for 14 days to increase ketogenesis; the intestinal tissues were then harvested for analysis. As shown in Figure $6 \mathrm{a}$, mice fed with the ketogenic diet demonstrated inhibition of HDAC as noted by the increased expression of H3K9ac. Importantly, mice fed with the ketogenic diet showed increased intestinal expression of MUC2 and p2 $1^{\text {Waf1 }}$ protein, suggesting that ketogenesis contributes to intestinal cell differentiation. Along with the increased differentiation, mTOR signaling was inhibited as shown by the decreased expression of p-S6 (Figure 6a). Collectively, these results suggest a cross-talk between ketogenesis and mTOR signaling during intestinal cell differentiation. Mice fed with the ketogenic diet increased expression of HMGCS2 in conjunction with decreased mTOR signaling in the small intestine (Figure 6a). As inhibition of mTOR has been shown to increase the expression of HMGCS2 mRNA and ketogenesis, ${ }^{32}$ feeding a ketogenic diet may increase the expression of HMGCS2 through the inhibition of mTOR signaling in intestinal cells. We did not find increased HMGCS2 expression in the colonic mucosa of mice fed with the ketogenic diet compared with mice fed a normal control chow (Supplementary Figure 3A). As the level of HMGCS2 is much higher in colon mucosa than that in small bowel mucosa (Supplementary Figure 3B), it may be difficult to 

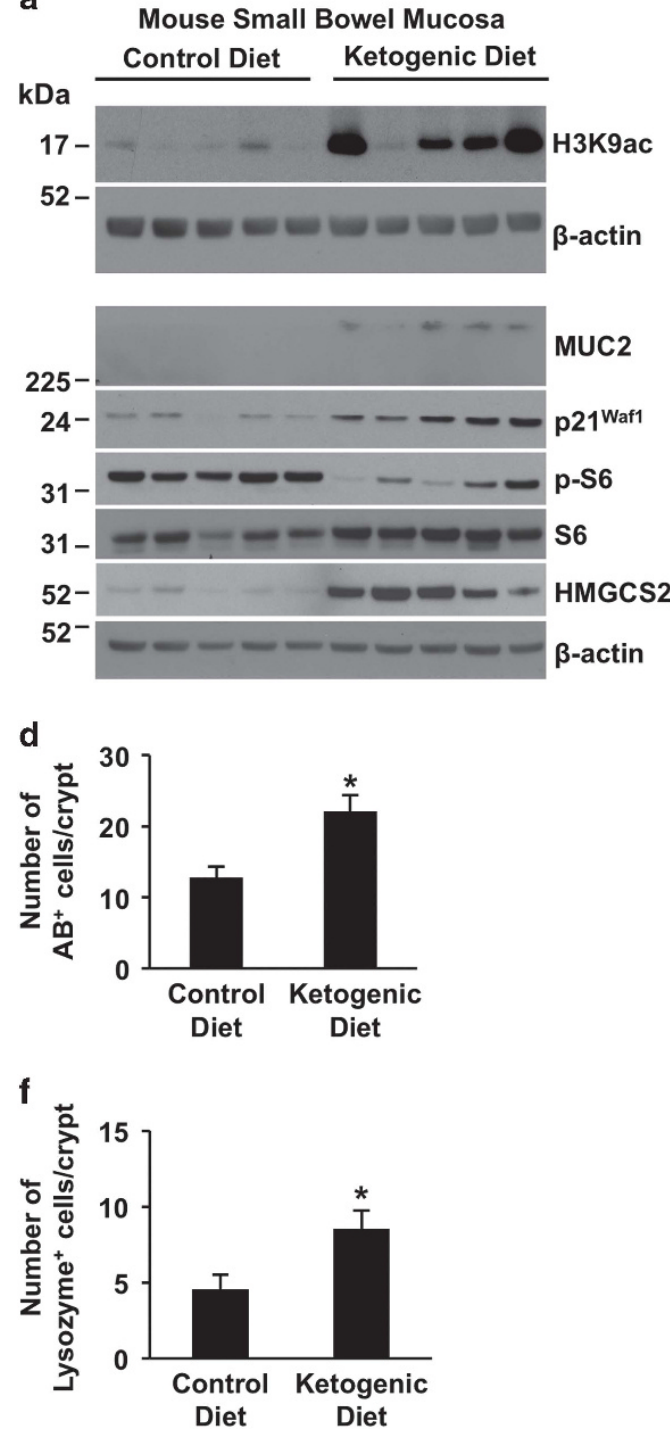

b
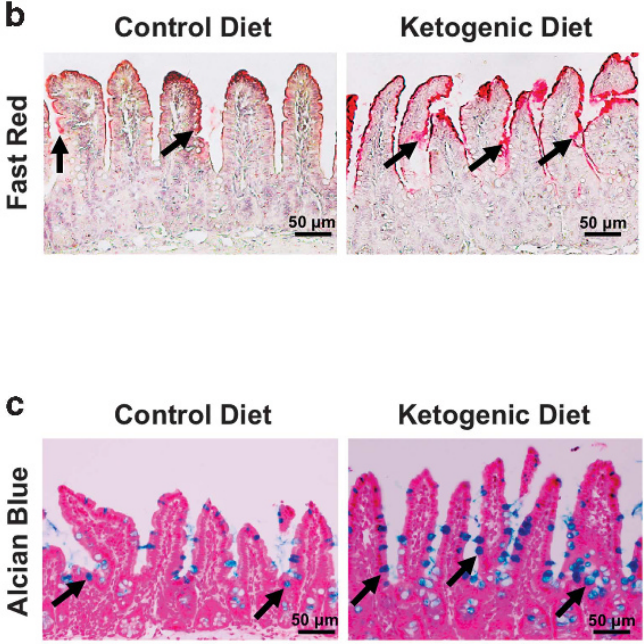

Ketogenic Diet

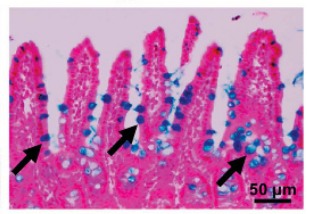

e

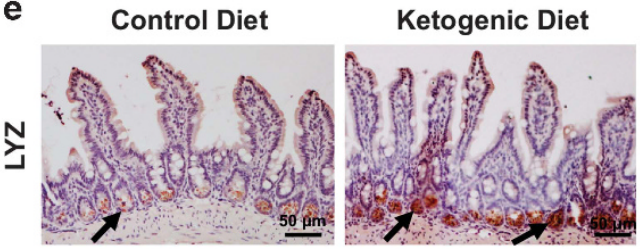

Control Diet

Ketogenic Diet

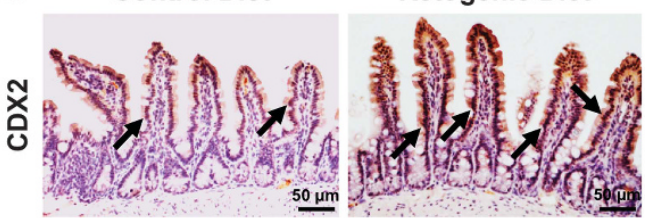

Figure 6 Enhanced intestinal cell differentiation by ketone diet. Mice were fed with normal chow $(n=5)$ or a ketogenic diet $(n=5)$ for 14 days. (a) Small intestinal mucosal protein lysates were extracted for western blot detection of H3K9ac, MUC2, p21 Waf1, p-S6, S6, HMGCS2 and $\beta$-actin protein expression. Each well represents a different mouse from the relevant group. (b) Representative Fast Red staining of the small intestine revealed an increase in IAP expression. (c) Representative AB staining of the small intestine revealed an increase in mucinous goblet cells in ketogenic diet-fed mice compared with control mice (arrows). (d) Quantification of AB-positive cells in control and ketogenic diet-fed mice. ( $n=15$ ( 3 crypts per mouse)), data represent mean \pm S.D.; ${ }^{*} P<0.01$ versus control diet). (e) Representative IHC staining of the small intestine for $L Y Z$ showed the increase in Paneth cells (arrows) in ketogenic diet-fed mice compared with control mice. (f) Quantification of LYZ-positive cells in control and ketogenic diet-fed mice. ( $n=15$ (3 crypts per mouse), data represent mean \pm S.D.; * $P<0.01$ versus control diet). (g) Representative IHC staining (arrows) for CDX2 demonstrated increased expression in the intestinal epithelium of ketogenic diet-fed mice compared with control mice. Scale bars $=50 \mu \mathrm{m}$

significantly increase the expression of basal HMGCS2 in the colonic epithelium.

We next determined the effect of increased ketogenesis on intestinal cell differentiation. In mice fed with the ketogenic diet, the intestine appeared normal by histology (Supplementary Figure 4A). Fast Red staining revealed a marked increase in IAP activity in the small bowel of mice fed with a ketogenic diet (Figure 6b), demonstrating increased enterocyte differentiation. MUC2 expression was markedly increased in the small bowel of mice fed the ketogenic diet as noted by Alcian blue (AB) staining and IHC (Figures $6 \mathrm{c}$, $d$ and Supplementary Figure $4 B$ ). Moreover, staining the intestinal sections from ketogenic diet-fed mice for $L Y Z$ revealed an obvious increase in Paneth cells (Figures $6 e$ and $f$ ). In agreement with the increased CDX2 expression mediated by treatment with $\beta \mathrm{HB}$ or overexpression of HMGCS2, increased expression of CDX2 was detected in the small bowel of mice fed the ketogenic diet (Figure 6g), demonstrating a ketogenesis-dependent regulation of CDX2. Therefore, results from our in vitro and in vivo studies show that ketogenesis is required for intestinal cell differentiation. Consistent with the decreased phosphorylation of S6 and increased expression of HMGCS2 (Figure 6a), decreased staining for $\mathrm{p}-\mathrm{S} 6$ and increased staining for HMGCS2 was also 

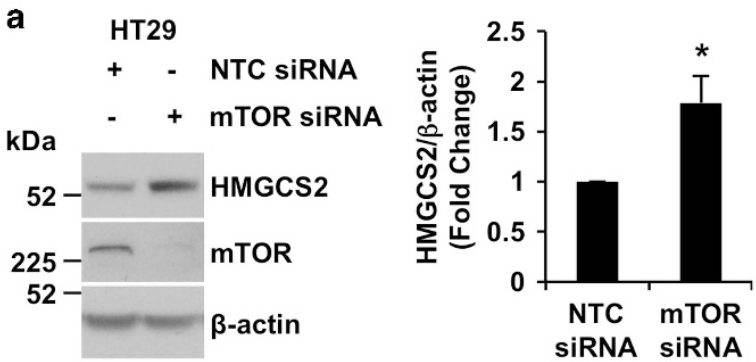

b

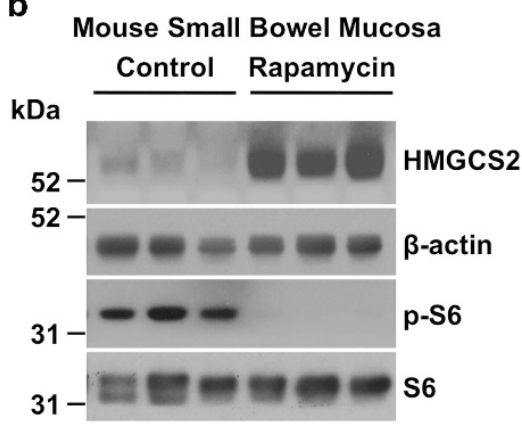

C

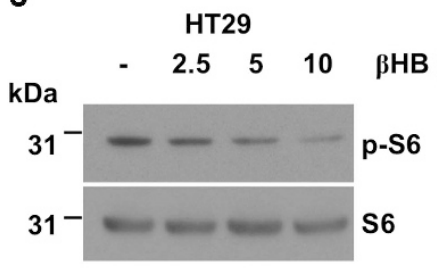

e

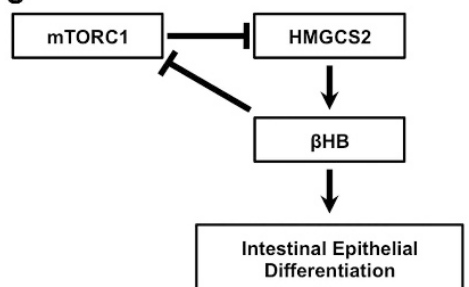

d

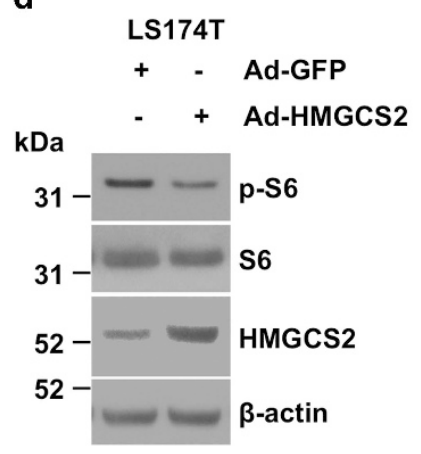

Figure 7 Cross-talk between mTORC1 and HMGCS2/ $\beta$ HB signaling. (a) HT29 cells were transfected with NTC or mTOR siRNA. After incubation for $48 \mathrm{~h}$, cells were lysed and western blot analysis was performed using antibodies against HMGCS2, mTOR and $\beta$-actin. Knockdown of mTOR increased HMGCS2 expression in HT29 cells. The images are representative of three independent experiments. HMGCS2 signals from three separate experiments were quantitated densitometrically and expressed as fold change with respect to $\beta$-actin. ( $n=3$, data represent mean \pm S.D.; ${ }^{*} P<0.01$ versus NTC siRNA). (b) Mouse small intestinal mucosal protein extracted from mice treated without (control, $n=3)$ or with rapamycin $(n=3)$ for 6 days. Western blotting was performed for the expression of the indicated proteins. Each well represents a different mouse from the relevant group. Treatment with rapamycin significantly increased HMGCS2 expression in intestinal epithelium. (c) HT29 cells were treated with $\beta$ HB at various dosages for $48 \mathrm{~h}$. Cells were lysed and western blot analysis was performed using antibodies against p-S6 and S6. Treatment with $\beta \mathrm{HB}$ inhibited mTOR signaling as shown by the decreased phosphorylation of S6. The images are representative of three independent experiments. (d) LS174T cells were infected with a recombinant adenovirus encoding the human HMGCS2 or vector control encoding GFP. After $48 \mathrm{~h}$, cells were lysed and western blot performed for the detection of the indicated proteins. Overexpression of HMGCS2 inhibited mTOR signaling as shown by the decreased expression of p-S6. p-S6 signals from three separate experiments were quantitated densitometrically and expressed as fold change with respect to total S6. ( $n=3$, data represent mean \pm S.D.; ${ }^{*} P<0.01$ versus GFP control). The images are representative of three independent experiments. (e) $\mathrm{mTOR} / \mathrm{HMGCS} / \beta \mathrm{HB}$ pathway model. Inhibition of mTORC1 increases ketogenesis and contributes to intestinal cell differentiation. In contrast, increase in ketogenesis inhibits mTOR signaling and induces differentiation. mTORC1 acts cooperatively with HMGCS2/ $\beta \mathrm{HB}$ to maintain intestinal homeostasis

noted in mice fed with a ketogenic diet compared with control mice (Supplementary Figures $4 \mathrm{C}$ and D). These results indicate that increased ketogenesis inhibits mTORC1 signaling in the intestinal epithelium.

Cross-talk between mTOR and HMGCS2/ $\beta$ HB in intestinal cells. Previously, we showed that decreased mTOR activity is associated with differentiation. ${ }^{33}$ Moreover, we showed that knockdown or inhibition of mTOR increases, whereas activation of mTOR reduces, the levels of intestinal differentiation markers. ${ }^{9,33,34}$ In this study, we showed that the expression of HMGCS2 is increased in differentiated cells (Figure $5 d$ ). To determine whether mTOR regulates HMGCS2 expression in intestinal cells, HT29 cells were transfected with mTOR siRNA or non-targeting control (NTC). As shown in Figure 7a, knockdown of mTOR increased HMGCS2 expression. To next determine whether mTOR inhibition increases HMGCS2 in vivo, mice were treated with rapamycin (4 mg/kg, i.p., daily for 6 days) and mucosal proteins were extracted from small bowel for analysis of HMGCS2 expression. As shown in Figure $7 \mathrm{~b}$, administration of rapamycin inhibited mTOR signaling as noted by the decreased expression of p-S6. Importantly, rapamycin markedly increased HMGCS2 protein expression in intestinal epithelium, demonstrating $\mathrm{mTORC} 1$ regulation of HMGCS2 expression in intestinal cells. In agreement with the increased HMGCS2 expression, mice treated with rapamycin showed increased differentiation in intestinal cells (Supplementary 
Figure 5), which is consistent with our previous findings showing that inhibition of mTOR by rapamycin increases differentiation in mouse intestinal epithelium. ${ }^{34}$

Finally, to determine whether the endogenous HDAC inhibitor $\beta \mathrm{HB}$ inhibits mTOR, HT29 cells were treated with $\beta \mathrm{HB}$ for $48 \mathrm{~h}$. As shown in Figure $7 \mathrm{c}, \beta \mathrm{HB}$ inhibited mTOR signaling as noted by the dose-dependent decrease in the expression of $\mathrm{p}-\mathrm{S} 6$. $\beta \mathrm{HB}$-induced inhibition of mTOR signaling was also noted in $\mathrm{FHs} 74$ Int human small intestinal epithelial cells (Supplementary Figure 6). As a result of mTOR inhibition, treatment with $\beta \mathrm{HB}$ increased HMGCS2 in FHs 74 Int cells (Supplementary Figure 6). Moreover, overexpression of HMGCS2 inhibited mTOR signaling in LS174T cells (Figure 7d). Taken together, our results identify a potential cross-talk between ketogenesis and mTOR signaling, which contributes to the process of intestinal cell differentiation.

\section{Discussion}

Previously, we have shown that inhibition of the PI3K/Akt/ mTOR signaling pathway increases intestinal cell differentiation. $9,13,21,33,34$ In our present study, we show that the enrichment of the ketone body, $\beta \mathrm{HB}$, and expression of the ketogenic enzyme, HMGCS2, was increased in differentiated intestinal cells. Consistent with these results, treatment with $\beta \mathrm{HB}$ increased, whereas knockdown of HMGCS2 inhibited, intestinal cell differentiation. Treatment with $\beta \mathrm{HB}$ or overexpression of HMGCS2 resulted in the induction of CDX2 expression and inhibition of mTOR signaling. Mice fed with a ketogenic diet show an induction of CDX2 and inhibition of mTORC1 signaling along with an increase in intestinal cell differentiation. Taken together, our results suggest that enhanced ketogenesis contributes to the process of intestinal cell differentiation.

We found that treatment with $\beta \mathrm{HB}$, which was enriched in differentiated cells, induces differentiation, thus suggesting that $\beta \mathrm{HB}$ acts as an endogenous regulator of intestinal homeostasis. Inhibition of HDACs contributes to intestinal cell differentiation. ${ }^{13,18}$ In our current study, we show that $\beta \mathrm{HB}$ inhibits HDACs in intestinal cells. Indeed, $\beta \mathrm{HB}$ acts as an endogenous inhibitor of HDACs in vitro and in vivo. ${ }^{17}$ Similar to butyrate, $\beta \mathrm{HB}$ is known to inhibit class I and Ila HDACs with an IC50 of 2-5 mM. ${ }^{17,35}$ An early event in the terminal differentiation of cells is their withdrawal from the cell cycle. ${ }^{36}$ Butyrate has been shown to potently suppress intestinal cell proliferation by acting as an HDAC inhibitor. ${ }^{37}$ Our previous study showed that butyrate increases $\mathrm{p} 21^{\text {Waf1 }}$ expression and induces cell cycle arrest associated with intestinal cell differentiation. ${ }^{13}$ Similar to butyrate, we found that $\beta \mathrm{HB}$, acting as an endogenous inhibitor of HDACs, induces p21 Waf1 expression and inhibits intestinal cell proliferation associated with the induction of differentiation. Given the extensive gene regulation by HDACs and the important role of HDACs in regulating intestinal cell differentiation, ${ }^{38,39} \beta \mathrm{HB}$ likely induces intestinal cell differentiation through inhibition of HDACs.

CDX2 is an intestine-specific transcription factor that is essential for the development and maintenance of the intestinal mucosal epithelium. ${ }^{24}$ CDX2 is essential for differentiation of gut stem cells into the four intestinal cell types. ${ }^{40}$ Ablation of $\mathrm{Cdx} 2$ in the intestine results in a decrease of mature enterocytes, and loss of goblet, enteroendocrine and Paneth cells. ${ }^{41}$ We showed that treatment with $\beta \mathrm{HB}$ or overexpression of ketogenic enzyme HMGCS2 increased CDX2 expression in intestinal cells. Moreover, our results showed that increased ketogenesis resulted in increased CDX2 expression along with increased differentiation in the intestinal epithelium of mice. Results from our in vitro and in vivo studies suggested that ketogenesis modulates intestinal differentiation through the induction of CDX2 expression. Our previous study demonstrated that treatment with butyrate, an inhibitor of HDAC, increased CDX2 expression in HT29 and Caco-2 cells. ${ }^{42}$ Butyrate has been shown to increase ketone body production through induction of HMGCS2 expression in human intestinal mucosa. ${ }^{14} \beta \mathrm{HB}$, acting as the causal agent for differentiation of intestinal cells exposed to butyrate, is supported by the fact that exposure of intestinal cells to $\beta \mathrm{HB}$ results in the terminal differentiation of these cells. As p2 $1^{\text {Waf1 }}$ is a CDX2 target gene, ${ }^{43}$ HMGCS2/ $\beta \mathrm{HB}$ increases $\mathrm{p} 21^{\text {Waf1 }}$ expression likely through the induction of CDX in intestinal cells, thus contributing to the differentiation process.

We have shown the importance of the PI3K/Akt/mTOR pathway in the regulation of intestinal cell proliferation and differentiation. ${ }^{7,13,44,45}$ However, the precise mechanisms of how mTOR regulates intestinal cell proliferation and differentiation remain to be fully defined. We found that HMGCS2/ $\beta \mathrm{HB}$ contributes to intestinal differentiation and, importantly, that inhibition of mTOR signaling increases expression of the ketogenic enzyme HMGCS2 in intestinal cells in vitro and in vivo. Our present results suggest that mTOR regulates intestinal differentiation, at least in part, through the regulation of ketogenesis. mTOR controls the expression of HMGCS2 mRNA and ketogenesis in liver cells through the inhibition of PPAR $a$-dependent transcription. ${ }^{32}$ Moreover, HMGCS2 is a direct target of c-Myc, which represses HMGCS2 transcriptional activity in intestinal cells. ${ }^{46}$ As activation of mTOR increases c-Myc expression in intestinal cells, ${ }^{47}$ it is likely that mTOR inhibition induces HMGCS2 through the alterations of PPAR $a$ - and c-Myc-dependent functions in intestinal cells. Our data also showed that treatment with $\beta \mathrm{HB}$ or overexpression of HMGCS2 in vitro, or induction in ketogenesis in vivo, resulted in the inhibition of mTOR signaling in intestinal cells. The inhibition of mTOR by ketone bodies was also demonstrated in the hippocampus and liver of rats fed ketogenic diet. ${ }^{48}$ Results from our laboratory and others have shown that inhibition of HDAC inhibits mTOR signaling in various cell types including intestinal cells. ${ }^{33,49,50}$ As $\beta \mathrm{HB}$ is an endogenous inhibitor of $\mathrm{HDAC}$, it is likely that HMGCS2/ $\beta \mathrm{HB}$ inhibits mTOR signaling through the inhibition of HDACs in intestinal cells. Together, our results show that $\mathrm{PI} / \mathrm{K} / \mathrm{Akt} / \mathrm{mTOR}$ signaling functions cooperatively with $\mathrm{HMGCS} 2 / \beta \mathrm{HB}$ in the regulation of intestinal cell differentiation.

Our results showed that knockdown of HMGCS2 attenuated the spontaneous differentiation in Caco-2 cells. These results further suggest that HMGCS2 is important for the maintenance of both colon and small intestinal cell homeostasis. The highly expressed HMGCS2 in colon epithelial cells noted in our current study suggests that colon is a ketogenic organ. Ketone bodies produced in colon, not only function as signaling molecules contributing to maintenance of colon 
epithelial cell differentiation, but may also enter into circulation and effect on the cells in other organs including small intestine. Therefore, perturbed expression of HMGCS2 in intestinal cells will result in the impaired intestinal cell differentiation. Increased differentiation in small intestine is an important mechanism during intestinal adaptation after small bowel resection. ${ }^{51}$ In addition, dysregulation of intestinal cell differentiation is associated with inflammatory bowel diseases and colorectal cancer. ${ }^{4,5}$ Indeed, HMGCS2 protein expression is downregulated preferentially in moderately and poorly differentiated colorectal adenocarcinomas. ${ }^{46}$ Moreover, we showed that $\beta$ HB inhibits HT29 and LS174T cell growth. Taken together, these results suggest that ketogenesis not only contributes to intestinal cell differentiation but may also inhibit abnormal growth of intestinal cells. Delineating the role of ketogenesis in the maintenance of intestinal homeostasis is crucial to our understanding of gut development and adaptation.

In conclusion, we show that ketogenesis contributes to intestinal cell differentiation, thus providing a better mechanistic understanding of ketogenesis and its potential beneficial effects in certain intestinal diseases. Taken together, our data support a novel role of ketogenesis, which acts cooperatively with mTOR signaling, in the regulation and the maintenance of intestinal epithelial homeostasis (Figure 7e).

\begin{abstract}
Materials and Methods
Cell culture, transfection and treatments. The human colon cancer cell lines, HT29 and Caco-2, were purchased from ATCC (Manassas, VA, USA) and were maintained in McCoy's 5A supplemented with $10 \%$ fetal calf serum (FCS), and MEM supplemented with 15\% FCS, respectively. HT29 and Caco-2 cells were tested for authentication via STR profiling in February 2016 by Genetica DNA Laboratories (LabCorp Specialty Testing Group; Burlington, NC, USA). Authentications were confirmed by a $100 \%$ match in comparison with the reference STR profiles from ATCC. In addition, both cell lines were tested for mycoplasma contamination by Genetica DNA Laboratories (LabCorp Specialty Testing Group) and were found to be negative. The human colon cancer cell line, LS174T, purchased in February 2016 from ATCC, was maintained in MEM supplemented with $10 \% \mathrm{FCS}$. FHs 74 Int human small intestinal epithelial cells were purchased in July 2016 from ATCC and maintained in Hybri-Care Medium ATCC 46-X supplemented with $30 \mathrm{ng} / \mathrm{ml}$ epidermal growth factor (Sigma-Aldrich) and 10\% FBS. Caco-2, LS174T and HT29 cell lines have served as useful models to delineate potential pathways leading to differentiation of enterocytes (characterized by expression of the brush-border enzymes IAP and SI, villin, and Keratin 20 (KRT20)), ${ }^{8,21,52}$ goblet cells (characterized by the increased MUC2 expression in HT29 and LS174T cells), ${ }^{9,34}$ and Paneth cells as shown by the induction of LYZ in HT29 cells. ${ }^{28}$ MISSION control shRNA and shRNAs to human HMGCS2 constructed in pLKO.1-puro vector were purchased from Sigma-Aldrich. The control shRNA (non-target shRNA control transduction particles, \# SHCO02V) contains four base-pair mismatches within the short-hairpin sequence to any known human or mouse genes. The lentivirus-mediated delivery of shRNA was carried out as we have previously described. ${ }^{9}$ Adenovirus vectors encoding GFP (Ad-GFP; control) and human HMGCS2 were from Vector BioLabs (Malvern, PA, USA). Flagtagged human HMGCS2 was from Origene (Rockville, MD, USA). Caco-2 cells were infected with the control shRNA or shRNA to human HMGCS2 lentiviral particles, and stably expressing cells were selected with puromycin $(5 \mu \mathrm{g} / \mathrm{ml})$. Human mTOR and NTC siRNA SMARTpool were purchased from Dharmacon, Inc. (Lafayette, CO, USA). HT29 cells were transfected with NTC or MTOR siRNA as we have previously described. ${ }^{34}$
\end{abstract}

SIRM analysis. Caco-2 cells were grown to different levels of confluency in MEM media containing $15 \%$ dialyzed FBS and $0.2 \%$ [U $\left.{ }^{13} \mathrm{C}\right]$-glucose $2 \mathrm{mM}$ $\left[\mathrm{U}-{ }^{13} \mathrm{C},{ }^{15} \mathrm{~N}\right]$-glutamine. The medium was sampled at $0,3,6,9$ and $24 \mathrm{~h}$ from each plate. Cells were quenched and harvested on the plate, and extracted and analyzed as described. ${ }^{20}$ The polar and non-polar components were prepared for NMR and mass spectrometry analyses as previously described. ${ }^{20}$ NMR spectra were recorded at $14.1 \mathrm{~T}$ on an Agilent DD2 spectrometer (Agilent Technologies, Santa Clara, CA, USA) equipped with automation and a $3 \mathrm{~mm}$ HCN cold probe. 1D proton spectra were recorded with an acquisition time of $2 \mathrm{~s}$ and a recycle time of $6 \mathrm{~s}$ with preset for solvent suppression. ${ }^{13} \mathrm{C}$-edited $1 \mathrm{D} \mathrm{HSQC}$ spectra were recorded with an acquisition time of $0.2 \mathrm{~s}$ and a recycle time of $2 \mathrm{~s}$, with adiabatic decoupling during the acquisition time. NMR signals were assigned according to in-house databases. Metabolites were quantified by peak integration and comparison with the internal standard DSS with corrections for partial saturation. GC-MS was carried out on samples derivatized with MTBSTFA using a Thermo LTQ (Thermo Fisher Scientific, Austin, TX, USA) GC-MS. Metabolites in GC-MS were assigned from their retention time and mass.

Western blot analysis. Total protein was resolved on a $10 \%$ polyacrylamide gel and transferred to polyvinylidene fluoride membranes. Membranes were incubated for $1 \mathrm{~h}$ at room temperature in blotting solution. Antibodies to CDX2 (\#3977), mTOR (\#2983), phospho-S6 (pS235/236, \#4858), S6 (\#2317), acetylhistone H3 (Lys9, \#9649) and p21 Waf1 (\# 2947, used for human cell lines) (all from Cell Signaling, Beverly, MA, USA), p21 ${ }^{\text {Waf1 }}$ (sc-397, used for mouse tissues, Santa Cruz, Dallas, TX, USA), MUC2 (S-1461, Epitomics Inc., Burlingame, CA, USA), villin (sc-7672, Santa Cruz), KRT20 (ab854, Abcam, Cambridge, MA, USA), HMGCS2 (ab137043, Abcam), Flag (F7425, Sigma, St. Louis, MO, USA) and $\beta$-actin (A1978, Sigma) were added, and following blotting with a horseradish peroxidase-conjugated secondary antibody, protein expression was visualized using an enhanced chemiluminescence $(E C L)$ detection system.

Quantitative real-time RT-PCR analysis. Total RNA was extracted and treated with DNase (RQ1, Promega, Madison, WI, USA). Synthesis of CDNA was performed with $1 \mu \mathrm{g}$ of total RNA using reagents in the TaqMan Reverse Transcription Reagents Kit (ABI, Applied Biosystems Inc., Foster City, CA, USA, \#N8080234). TagMan probe and primers for human SI, IAP, KRT20, MUC2, LYZ, p21 ${ }^{\text {Waf1 }}$, CDX2 and GAPDH were purchased from Applied Biosystems (Foster City, CA, USA). Quantitative real-time RT-PCR analysis was performed with an Applied Biosystems Prism 7000HT Sequence Detection System using TaqMan universal PCR master mix as we have described previously.

Immunohistochemistry, AB staining and IAP staining. Immunohistochemistry $(\mathrm{IHC})$ and $\mathrm{AB}$ staining were performed as we have described previously. ${ }^{34}$ Tissue was processed for routine IHC staining using the following antibodies: rabbit anti-LYZ (Diagnostic BioSystems, Pleasanton, CA, USA, RP 02805), anti-MUC2 (Santa Cruz, SC15334), anti-phospho-S6 (pS235/236) (Cell Signaling, \#4858), and anti-CDX2 (Biogenex, Fremont, CA, USA, MU392A-UC). Negative controls (including no primary antibody or isotype-matched mouse immunoglobulin $G$ ) were used in each assessment. $A B$ staining was performed according to standard protocol using AB pH 2.5 Stain Kit (Dako, Carpinteria, CA, USA, AR160). IAP staining was performed using Vulcan Fast Red Chromogen kit (Biocare Medical, Concord, CA, USA, FR805), following the manufacturer's recommendations. Formalin-fixed, paraffin-embedded tissue samples of normal human small bowel were used for HMGCS2 staining using anti-HMGCS2 antibody (ab137043, Abcam).

Mice. C57BL/6 mice were obtained from the Jackson Laboratory (Sacramento, CA, USA) and bred in our facility. Mice were maintained on a 12- $\mathrm{h}$ light/dark schedule in filter top isolators with autoclaved water under specific pathogen-free conditions, and fed autoclaved standard laboratory chow ad libitum (2918 Teklad Rodent Diet (Envigo, Indianapolis, IN, USA) consisting of $6.2 \%$ fat, $18 \%$ protein and $44 \%$ carbohydrate wt/wt). Six mice (male, 16 weeks) were randomized to control versus rapamycin groups. Rapamycin (LC Laboratories, Woburn, MA, USA), administered by i.p. injection daily for 6 days at $4 \mathrm{mg} / \mathrm{kg}$, was reconstituted in absolute ethanol at $10 \mathrm{mg} / \mathrm{ml}$ and diluted in 5\% Tween 80 (Sigma) and 5\% PEG-400 (Hampton Research, Aliso Viejo, CA, USA) before injection as we described previously. ${ }^{34}$ To model a ketogenic diet and elevate ketogenesis in vivo, we fed mice with 1,3-butanediol ketone diesters. ${ }^{30}$ Ten mice (male, 16 weeks) were randomized to control diet versus ketogenic diet groups. To prepare the ketogenic diet, standard chow food pellets were ground in a mixer, $200 \mathrm{~g}$ of ground diet was mixed with $50 \mathrm{ml}$ of ( \pm )-1,3-Butanediol (B84785, Sigma-Aldrich) and shaken to form round pellets. Mice were fed with control normal chow diet or the ketogenic diet ad libitum for 14 days; normal chow and ketogenic diet were refreshed every $72 \mathrm{~h}$.

The ileum and cecum were harvested, opened and washed with ice-cold PBS. Half of the sample was used for $\mathrm{IHC}$; the mucosa from the other portion was scraped with 
glass slides, placed into cell lysis buffer and immediately snap frozen in liquid $\mathrm{N}_{2}$. Samples were homogenized in cell lysis buffer by stainless steel blend bead beating $\left(0.9-2.0 \mathrm{~mm} ; 5 \mathrm{~m}, 4^{\circ} \mathrm{C}\right.$ ) using a Bullet Blender (Next Advance Inc., Averill Park, NY, USA). Cell lysis buffer (Cell Signaling) was supplemented with $1 \mathrm{mM}$ PMSF and protease inhibitor cocktails (complete mini and complete ultra, EDTA-free; 1 tablet per $10 \mathrm{ml}$ lysis buffer; Roche, Indianapolis, IN, USA). All animal procedures were conducted with approval and in compliance with University of Kentucky Institutional Animal Care and Use Committee.

Statistical analysis. Comparisons of the number of $\mathrm{AB}^{+}$and $\mathrm{LYZ}^{+}$in the intestine were performed between control diet and ketogenic diet mice using the linear mixed model to account for multiple observations from multiple crypts per mouse. Pairwise comparisons for two groups were performed using two-sample $t$-test or analysis of variance for multiple groups with contrast statements. Adjustment in $P$-values because of multiple pairwise testing between groups was performed using the Holm's step-down procedure. Comparisons were performed for control versus $\beta \mathrm{HB}$ treatment, control shRNA versus HMGCS2 shRNA, or GFP versus HMGCS2. Bar graphs represent mean \pm S.D. levels in each group. $P$-values $<0.05$ were considered statistically significant.

For the in vivo mice study, sufficient sample size was utilized to provide at least $80 \%$ power to detect a large effect size (1.8 mean differences in S.D. units) based on a two-group comparison, two-sided test with $5 \%$ significance level. All data from animal samples with measurement of study endpoints were included in the analysis. Mice within a cage were randomized to both groups in the experiment to ensure balance in treatment group assignments across all cages. The animals were randomly selected for group assignment without preference to size or other confounding factors. A different individual performed measurements on study endpoints to ensure blinding from group assignment. Furthermore, only animal IDs without information on group assignment were available to staff performing the endpoint evaluation. Parametric tests were utilized after evaluating distribution of data (e.g., percentiles, mean and median levels), test for normality (e.g., KolmogorovSmirnov test, if sufficient sample sizes) and test for homogeneity of variance assumptions across groups (folded F-test, Brown-Forsythe test).

\section{Conflict of Interest}

The authors declare no conflict of interest.

Acknowledgements. We thank HN Russell-Simmons for manuscript preparation; D Napier for tissue sectioning and staining; EY Lee for consultation and assessment of histological sections and IHC; the Biospecimen and Tissue Procurement, Redox Metabolism, and Biostatistics and Bioinformatics Shared Resource Facilities of the University of Kentucky Markey Cancer Center (supported by National Cancer Institute grant P30 CA177558). This work was further supported by National Institutes of Health grant R01 DK48498. MS and NMR analyses were carried out in the CESB facilities with support, in part, from U24 DK097215 (RM Higashi, Program Director)

1. Yeung TM, Chia LA, Kosinski CM, Kuo CJ. Regulation of self-renewal and differentiation by the intestinal stem cell niche. Cell Mol Life Sci 2011; 68: 2513-2523.

2. De Mey JR, Freund JN. Understanding epithelial homeostasis in the intestine: an old battlefield of ideas, recent breakthroughs and remaining controversies. Tissue Barriers 2013; 1: $\mathrm{e} 24965$

3. Gunther C, Neumann H, Neurath MF, Becker C. Apoptosis, necrosis and necroptosis: cell death regulation in the intestinal epithelium. Gut 2013; 62: 1062-1071.

4. Gersemann M, Wehkamp J, Stange EF. Innate immune dysfunction in inflammatory bowel disease. J Intern Med 2012; 271: 421-428.

5. Hammoud SS, Cairns BR, Jones DA. Epigenetic regulation of colon cancer and intestinal stem cells. Curr Opin Cell Biol 2013; 25: 177-183.

6. Clark JA, Doelle SM, Halpern MD, Saunders TA, Holubec H, Dvorak K et al. Intestinal barrier failure during experimental necrotizing enterocolitis: protective effect of EGF treatment. Am J Physiol Gastrointest Liver Physiol 2006; 291: G938-G949.

7. Shao J, Evers BM, Sheng H. Roles of phosphatidylinositol $3^{\prime}$-kinase and mammalian target of rapamycin/p70 ribosomal protein S6 kinase in K-Ras-mediated transformation of intestinal epithelial cells. Cancer Res 2004; 64: 229-235.

8. Wang $Q$, Zhou $Y$, Jackson LN, Johnson SM, Chow CW, Evers BM. Nuclear factor of activated T cells (NFAT) signaling regulates PTEN expression and intestinal cell differentiation. Mol Biol Cell 2011; 22: 412-420.

9. Zhou Y, Wang Q, Guo Z, Weiss HL, Evers BM. Nuclear factor of activated T-cell c3 inhibition of mammalian target of rapamycin signaling through induction of regulated in development and DNA damage response 1 in human intestinal cells. Mol Biol Cell 2012: 23 : 2963-2972.

10. Wang Q, Zhou Y, Rychahou P, Liu C, Weiss HL, Evers BM. NFAT5 represses canonical Wn signaling via inhibition of beta-catenin acetylation and participates in regulating intestinal cell differentiation. Cell Death Dis 2013; 4: e671.

11. Shyh-Chang N, Daley GQ, Cantley LC. Stem cell metabolism in tissue development and aging. Development 2013; 140: 2535-2547.

12. Stringari $\mathrm{C}$, Edwards RA, Pate KT, Waterman ML, Donovan PJ, Gratton E. Metabolic trajectory of cellular differentiation in small intestine by phasor fluorescence lifetime microscopy of NADH. Sci Rep 2012; 2: 568

13. Wang Q, Zhou Y, Wang X, Evers BM. p27 Kip1 nuclear localization and cyclin-dependent kinase inhibitory activity are regulated by glycogen synthase kinase-3 in human colon cancer cells. Cell Death Differ 2008; 15: 908-919.

14. Vanhoutvin SA, Troost FJ, Hamer HM, Lindsey PJ, Koek GH, Jonkers DM et al. Butyrateinduced transcriptional changes in human colonic mucosa. PLoS One 2009; 4: e6759.

15. Alexandre A. Suggested involvement of ketone bodies in the pathogenesis of the metabolic syndrome. Med Hypotheses 2013; 80: 578-581.

16. Newman JC, Verdin E. Ketone bodies as signaling metabolites. Trends Endocrinol Metab 2014; 25: 42-52

17. Shimazu T, Hirschey MD, Newman J, He W, Shirakawa K, Le Moan N et al. Suppression of oxidative stress by beta-hydroxybutyrate, an endogenous histone deacetylase inhibitor. Science 2013; 339: 211-214.

18. Tou L, Liu Q, Shivdasani RA. Regulation of mammalian epithelial differentiation and intestine development by class I histone deacetylases. Mol Cell Biol 2004; 24: 3132-3139.

19. Kumar SP, Roy SJ, Tokumo K, Reddy BS. Effect of different levels of calorie restriction on azoxymethane-induced colon carcinogenesis in male F344 rats. Cancer Res 1990; 50: 5761-5766.

20. Lane AN, Fan TW, Higashi RM. Isotopomer-based metabolomic analysis by NMR and mass spectrometry. Biophys Tools Biologists 2008; 84: 541-588.

21. Wang Q, Wang X, Hernandez A, Kim S, Evers BM. Inhibition of the phosphatidylinositol 3 kinase pathway contributes to HT29 and Caco-2 intestinal cell differentiation. Gastroenterology 2001; 120: 1381-1392.

22. Mak AB, Nixon AM, Kittanakom S, Stewart JM, Chen Gl, Curak J et al. Regulation of CD133 by HDAC6 promotes beta-catenin signaling to suppress cancer cell differentiation. Cell Rep 2012; 2: 951-963.

23. Evers BM. Intestinal cell differentiation: cellular mechanisms and the search for the perfect model focus on "involvement of p21(WAF1/Cip1) and p27(Kip1) in intestinal epithelial cell differentiation". Am J Physiol 1999; 276(6 Pt 1): C1243-C1244.

24. Saad RS, Ghorab Z, Khalifa MA, Xu M. CDX2 as a marker for intestinal differentiation: its utility and limitations. World J Gastrointest Surg 2011; 3: 159-166.

25. Hegardt FG. Mitochondrial 3-hydroxy-3-methylglutaryl-CoA synthase: a control enzyme in ketogenesis. Biochem J 1999; 338 Pt 3 569-582.

26. Schwartz B, Avivi-Green C, Polak-Charcon S. Sodium butyrate induces retinoblastoma protein dephosphorylation, p16 expression and growth arrest of colon cancer cells. Mol Cell Biochem 1998; 188: 21-30.

27. Burger-van Paassen N, Vincent A, Puiman PJ, van der Sluis M, Bouma J, Boehm G et al. The regulation of intestinal mucin MUC2 expression by short-chain fatty acids: implications for epithelial protection. Biochem J 2009; 420: 211-219.

28. Heuberger J, Kosel F, Qi J, Grossmann KS, Rajewsky K, Birchmeier W. Shp2/MAPK signaling controls gobletpaneth cell fate decisions in the intestine. Proc Natl Acad Sci USA 2014; 111: 3472-3477.

29. Helenius TO, Misiorek JO, Nystrom JH, Fortelius LE, Habtezion A, Liao J et al. Keratin 8 absence down-regulates colonocyte HMGCS2 and modulates colonic ketogenesis and energy metabolism. Mol Biol Cell 2015; 26: 2298-2310.

30. Youm YH, Nguyen KY, Grant RW, Goldberg EL, Bodogai M, Kim D et al. The ketone metabolite beta-hydroxybutyrate blocks NLRP3 inflammasome-mediated inflammatory disease. Nat Med 2015; 21: 263-269.

31. Tate RL, Mehlman MA, Tobin RB. Metabolic fate of 1,3-butanediol in the rat: conversion to -hydroxybutyrate. J Nutr 1971; 101: 1719-1726.

32. Sengupta S, Peterson TR, Laplante M, Oh S, Sabatini DM. mTORC1 controls fastinginduced ketogenesis and its modulation by ageing. Nature 2010; 468: 1100-1104.

33. Zhou $\mathrm{Y}$, Wang Q, Weiss HL, Evers BM. Nuclear factor of activated T-cells 5 increases intestinal goblet cell differentiation through an mTOR/Notch signaling pathway. Mol Biol Cell 2014; 25: 2882-2890.

34. Zhou Y, Rychahou P, Wang Q, Weiss HL, Evers BM. TSC2/mTORC1 signaling controls Paneth and goblet cell differentiation in the intestinal epithelium. Cell Death Dis 2015; 6 : e1631.

35. Newman JC, Verdin E. beta-hydroxybutyrate: much more than a metabolite. Diabetes Res Clin Pract 2014; 106: 173-181.

36. Zavitz KH, Zipursky SL. Controlling cell proliferation in differentiating tissues: genetic analysis of negative regulators of G1-> S-phase progression. Curr Opin Cell Biol 1997; 9: 773-781.

37. Kaiko GE, Ryu SH, Koues OI, Collins PL, Solnica-Krezel L, Pearce EJ et al. The colonic crypt protects stem cells from microbiota-derived metabolites. Cell 2016; 165: 1708-1720.

38. Shen Y, Wei W, Zhou DX. Histone acetylation enzymes coordinate metabolism and gene expression. Trends Plant Sci 2015; 20: 614-621.

39. Roostaee A, Benoit YD, Boudjadi S, Beaulieu JF. Epigenetics in intestinal epithelial cell renewal. J Cell Physiol 2016; 231: 2361-2367. 
40. Stringer EJ, Duluc I, Saandi T, Davidson I, Bialecka M, Sato T et al. Cdx2 determines the fate of postnatal intestinal endoderm. Development 2012; 139: 465-474.

41. Hryniuk $A$, Grainger $S$, Savory JG, Lohnes $D$. Cdx function is required for maintenance of intestinal identity in the adult. Dev Biol 2012; 363: 426-437.

42. Domon-Dell C, Wang Q, Kim S, Kedinger M, Evers BM, Freund JN. Stimulation of the intestinal Cdx2 homeobox gene by butyrate in colon cancer cells. Gut 2002; 50: 525-529.

43. Bai $Y Q$, Miyake S, Iwai T, Yuasa Y. CDX2, a homeobox transcription factor, upregulates transcription of the p21/WAF1/CIP1 gene. Oncogene 2003; 22: 7942-7949.

44. Gulhati P, Cai Q, Li J, Liu J, Rychahou PG, Qiu S et al. Targeted inhibition of mammalian target of rapamycin signaling inhibits tumorigenesis of colorectal cancer. Clin Cancer Res 2009; 15: 7207-7216.

45. Wang $Q$, Zhou $Y$, Wang $X$, Chung DH, Evers BM. Regulation of PTEN expression in intestinal epithelial cells by c-Jun NH2-terminal kinase activation and nuclear factor-kappaB inhibition. Cancer Res 2007; 67: 7773-7781.

46. Camarero N, Mascaro C, Mayordomo C, Vilardell F, Haro D, Marrero PF. Ketogenic HMGCS2 is a c-Myc target gene expressed in differentiated cells of human colonic epithelium and down-regulated in colon cancer. Mol Cancer Res 2006; 4: 645-653.
47. Fu Z, Kim J, Vidrich A, Sturgill TW, Cohn SM. Intestinal cell kinase, a MAP kinase-related kinase, regulates proliferation and G1 cell cycle progression of intestinal epithelial cells. Am J Physiol Gastrointest Liver Physiol 2009; 297: G632-G640.

48. McDaniel SS, Rensing NR, Thio LL, Yamada KA, Wong M. The ketogenic diet inhibits the mammalian target of rapamycin (mTOR) pathway. Epilepsia 2011; 52: e7-11.

49. Zhang P, Guo Z, Wu Y, Hu R, Du J, He X et al. Histone deacetylase inhibitors inhibit the proliferation of gall bladder carcinoma cells by suppressing AKT/mTOR signaling. PLOS One 2015; 10: e0136193.

50. Gonneaud A, Turgeon N, Boudreau F, Perreault N, Rivard N, Asselin C. Distinct roles for intestinal epithelial cell-specific Hdac1 and Hdac2 in the regulation of murine intestinal homeostasis. J Cell Physiol 2016; 231: 436-448.

51. Helmrath MA, Fong JJ, Dekaney CM, Henning SJ. Rapid expansion of intestinal secretory lineages following a massive small bowel resection in mice. Am J Physiol Gastrointest Liver Physiol 2007; 292: G215-G222.

52. Sadanandam A, Lyssiotis CA, Homicsko K, Collisson EA, Gibb WJ, Wullschleger S et al. A colorectal cancer classification system that associates cellular phenotype and responses to therapy. Nat Med 2013; 19: 619-625.

Supplementary Information accompanies this paper on Cell Death and Differentiation website (http://www.nature.com/cdd) 